\title{
Análise de redes sociais - aplicação nos estudos de transferência da informação
}

\author{
Regina Maria Marteleto \\ Programa de Pós-Graduação em Ciência da Informação, \\ MCT/IBICT - UFRJ/ECO
}

\section{Resumo}

Discute-se sobre a aplicação da metodologia de análise de redes sociais nos estudos do fluxo e transferência da informação, a partir da apresentação dos resultados de pesquisa desenvolvida junto a movimentos sociais organizados nos subúrbios da Leopoldina, na cidade do Rio de Janeiro. Para estudar os fluxos de informação e as estruturas de comunicação de grupos delimitados, procurouse perceber como as informações circulam e são empregadas como recurso nas lutas por melhores condições de vida.

Foram aplicadas algumas medidas da metodologia de análise de redes sociais, combinadas com instrumentos da metodologia qualitativa. Conclui-se que, tal como apontou a análise de redes, alguns personagens são responsáveis pela dinamização das redes, ocupando posições estratégicas, que Ihes garantem, inclusive, o reconhecimento dos demais agentes. Além disso, percebe-se que no interior dessas redes, na constante tensão entre as diferenças que ela comporta, formam-se "redes de conhecimentos", que alimentam e redefinem constantemente as ações.

\section{Palavras-chave}

Redes sociais; Movimentos sociais; Informação; Comunicação; Conhecimento

\section{Analysis of social networks - application in the studies of information transfer}

\footnotetext{
Abstract

The social networks analysis method applied to information flow and transfer studies is discussed through the findings of a research project carried out upon organized social movements at Leopoldina suburbs (Rio de Janeiro). To study circumscribed groups information flows and communication structures, the ways informations circulate and are applied as resources of the struggle for better living condition were observed. Some measurements of the social networks analysis method matched with qualitative method instruments were applied. The results showed that some role players are responsible for networks dynamization, holding strategic positions, that also ensure them, the recognition by other agents. It can be noted that in the middle of these networks, through the constant tension between differences comprised, "knowledge networks" are formed, which in turn feed and redefine actions.
}

\section{Keywords}

Social Networks; Social Movements; Information; Communication; Knowledge

\section{INTRODUÇÃO}

Este artigo pretende apresentar um estudo de transferência de informação em redes de movimentos sociais ${ }^{1}$. Para tanto, foi empregada a metodologia de Análise de Redes Sociais, com o objetivo de perceber os fluxos de informação e as construções sociais e simbólicas dos grupos estudados. A pesquisa foi ambientada na região da Leopoldina, subúrbio do Rio de Janeiro, e objetivou compreender a informação e a comunicação como instrumentos de mobilização nos movimentos sociais locais.

A organização do estudo está baseada em uma idéia que Leroy-Pineau (1994:24) chamou de "eficácia" das redes. Segundo a autora, o conceito de rede tem, em termos gerais, uma dupla aplicação (ou eficácia): a "utilização estática" e a "utilização dinâmica".

A utilização estática explora a rede estrutura, ou seja, lança mão da idéia de rede para melhor compreender a sociedade ou um grupo social por sua estrutura, seus nós e suas ramificações. Essa foi a contribuição que o enfoque de redes sociais deu à sociologia e a outras ciências.

A utilização dinâmica explicita a rede sistema, o que significa trabalhar as redes como uma estratégia de ação no nível pessoal ou grupal, para gerar instrumentos de mobilização de recursos.

Para o pesquisador, a idéia de redes tem a utilização estática. Para os grupos estudados, a utilização dinâmica.

Neste estudo, foram utilizados esses dois caminhos, ou seja, tanto o conceito de redes, que contribuiu ao trazer uma nova metodologia para as ciências sociais, quanto as novas possibilidades que ele traz, na prática, para grupos organizados em movimentos sociais. 


\section{REDES NAS CIÊNCIAS SOCIAIS}

Entre as diversas significações que "rede" (network) vem adquirindo, apesar de não se limitar somente a elas, servem ao propósito deste artigo as seguintes: sistema de nodos e elos; uma estrutura sem fronteiras; uma comunidade não geográfica; um sistema de apoio ou um sistema físico que se pareça com uma árvore ou uma rede. A rede social, derivando deste conceito, passa a representar um conjunto de participantes autônomos, unindo idéias e recursos em torno de valores e interesses compartilhados.

O conceito de redes é tributário de um conflito permanente entre diferentes correntes nas ciências sociais, que criam os pares dicotômicos - indivíduo/sociedade; ator/ estrutura; abordagens subjetivistas/objetivistas; enfoques micro ou macro da realidade social -, colocando cada qual a ênfase analítica em uma das partes. Por exemplo, a antropologia estrutural entende as redes como descritivas, servindo para identificar o caráter perene das organizações e dos comportamentos sociais. Já a linha do individualismo metodológico desconstrói essa concepção, privilegiando o ponto de vista do agente que produz sentido, e as relações sociais na formação do seu agir. As redes surgem como um novo instrumento face aos determinismos institucionais.

Por outro lado, o trabalho pessoal em redes de conexões é tão antigo quanto a história da humanidade, mas, apenas nas últimas décadas, as pessoas passaram a percebê-lo como uma ferramenta organizacional. "O que é novo no trabalho em redes de conexões é sua promessa como uma forma global de organização com raízes na participação individual. Uma forma que reconhece a independência enquanto apóia a interdependência. O trabalho em redes de conexões pode conduzir a uma perspectiva global baseada na experiência pessoal" (Lipnack \& Stamps, 1992: 19).

Houve grande investimento acadêmico nos estudos de redes a partir do campo das relações internacionais, tendo significação na história recente das ciências políticas. A origem da reflexão se dá ao fim da II Guerra Mundial e tem progresso com o fim da Guerra Fria, quando há redefinição dos atores nas relações internacionais. Novos caminhos de pesquisa surgem, nascidos a partir da reflexão de ordem e desordem nos sistemas políticos, ligados à elaboração da noção de globalização (Colonomos, 1995).

Nas redes sociais, há valorização dos elos informais e das relações, em detrimento das estruturas hierárquicas. Hoje o trabalho informal em rede é uma forma de organização humana presente em nossa vida cotidiana e nos mais diferentes níveis de estrutura das instituições modernas.
O estudo das redes coloca assim em evidência um dado da realidade social contemporânea que ainda está sendo pouco explorado, ou seja, de que os indivíduos, dotados de recursos e capacidades propositivas, organizam suas ações nos próprios espaços políticos em função de socializações e mobilizações suscitadas pelo próprio desenvolvimento das redes. Mesmo nascendo em uma esfera informal de relações sociais, os efeitos das redes podem ser percebidos fora de seu espaço, nas interações com o Estado, a sociedade ou outras instituições representativas. Decisões micro são influenciadas pelo macro, tendo a rede como intermediária.

\section{METODOLOGIA DE ANÁLISE DE REDES SOCIAIS}

Desde os estudos clássicos de redes sociais até os mais recentes, concorda-se que não existe uma "teoria de redes sociais" e que o conceito pode ser empregado com diversas teorias sociais, necessitando de dados empíricos complementares, além da identificação dos elos e relações entre indivíduos ${ }^{2}$. A análise de redes pode ser aplicada no estudo de diferentes situações e questões sociais.

A análise de redes estabelece um novo paradigma na pesquisa sobre a estrutura social. Para estudar como os comportamentos ou as opiniões dos indivíduos dependem das estruturas nas quais eles se inserem, a unidade de análise não são os atributos individuais (classe, sexo, idade, gênero), mas o conjunto de relações que os indivíduos estabelecem através das suas interações uns com os outros. A estrutura é apreendida concretamente como uma rede de relações e de limitações que pesa sobre as escolhas, as orientações, os comportamentos, as opiniões dos indivíduos.

A análise de redes não constitui um fim em si mesma. Ela é o meio para realizar uma análise estrutural cujo objetivo é mostrar em que a forma da rede é explicativa dos fenômenos analisados. O objetivo é demonstrar que a análise de uma díade (interação entre duas pessoas) só tem sentido em relação ao conjunto das outras díades da rede, porque a sua posição estrutural tem necessariamente um efeito sobre sua forma, seu conteúdo e sua função. Portanto, a função de uma relação depende da posição estrutural dos elos, e o mesmo ocorre com o status e o papel de um ator. Uma rede não se reduz a uma simples soma de relações, e a sua forma exerce uma influência sobre cada relação (Degenne \& Forse, 1994: 7-12). 
As redes nas ciências sociais designam normalmente - mas não exclusivamente - os movimentos fracamente institucionalizados, reunindo indivíduos e grupos em uma associação cujos termos são variáveis e sujeitos a uma reinterpretação em função dos limites que pesam sobre suas ações. É composta de indivíduos, grupos ou organizações, e sua dinâmica está voltada para a perpetuação, a consolidação e o desenvolvimento das atividades dos seus membros.

Nos espaços informais, as redes são iniciadas a partir da tomada de consciência de uma comunidade de interesses e/ou de valores entre seus participantes. Entre as motivações mais significativas para o desenvolvimento das redes estão os assuntos que relacionam os níveis de organização social-global, nacional, regional, estadual, local, comunitário. Independentemente das questões que se busca resolver, muitas vezes a participação em redes sociais envolve direitos, responsabilidades e vários níveis de tomada de decisões.

De forma diferente das instituições, as redes não supõem necessariamente um centro hierárquico e uma organização vertical, sendo definidas pela multiplicidade quantitativa e qualitativa dos elos entre os seus diferentes membros, orientada por uma lógica associativa. Sua estrutura extensa e horizontal não exclui a existência de relações de poder e de dependência nas associações internas e nas relações com unidades externas (Colonomos, 1995: 22-24).

Estudar a informação através das redes sociais significa considerar as relações de poder que advêm de uma organização não-hierárquica e espontânea e procurar entender até que ponto a dinâmica do conhecimento e da informação interfere nesse processo.

\section{REDES DE MOVIMENTOS SOCIAIS}

Os movimentos sociais em geral designam um tipo de ação coletiva orientada para a mudança, em que uma coletividade de pessoas é dirigida, de modo nãohierárquico, por um ator social. Os movimentos logram maior duração e integração e são eles em geral que originam as organizações, os partidos, as associações, a partir de uma consciência de grupo e das afinidades percebidas por indivíduos submetidos às mesmas pressões sociais ou que enfrentam idênticas dificuldades e obstáculos (Dicionário de Ciências Sociais, 1987).

Numerosos estudos, nas últimas décadas, têm mostrado as mudanças no perfil e na dinâmica dos movimentos sociais. A mudança básica estaria relacionada à alteração do seu foco mobilizador e reivindicatório da esfera da produção e do trabalho para as "condições de vida da população". Essa nova face dos movimentos os caracteriza como ações de exigência de atendimento de novas necessidades e, portanto, como lutas pela ampliação do acesso ao espaço político e aos benefícios do desenvolvimento econômico ${ }^{3}$.

Os novos movimentos sociais surgem como conseqüência das contradições geradas na desigualdade na propriedade, na apropriação do produto social e no planejamento produtivo. Embora sejam universais tais contradições, é a partir do seu contexto social específico que os movimentos as enfrentam e associam às carências básicas da população. Seu projeto fundamental é a construção da democracia em dupla perspectiva: institucional e das relações sociais ou "cultura democrática", a qual depende da capacidade de articulação de um espectro mais amplo de atores sociais e da reconstrução prática da cidadania. É um processo que aponta para a liberdade, para a igualdade, para a autonomia, para a autogestão, para o respeito à vida, para a representação política alternativa pelo próprio movimento, que são valores inerentes à cidadania e à sua conquista e exercício (Senna Filho, 1994).

Nos países pobres, o atendimento da agenda de reivindicações dos novos movimentos sociais tem sido o mais forte elemento de construção democrática.

Nas análises mais recentes, o enfoque das redes está sendo empregado para a leitura mais abrangente dos elementos constitutivos dos movimentos, como o papel dos atores que os organizam e orientam; a coordenação social ou constituição dos movimentos e as dificuldades de organizar uma coletividade de pessoas de modo nãohierárquico; e o problema da estratégia política ou orientação para a mudança.

A reivindicação de políticas sociais continua sendo necessária e justa, mas não é mais a única estratégia dos movimentos. Pensa-se em um caminho complementar, de solução autônoma dos problemas por parte da sociedade, já que o Estado se mostra inoperante ou ausente. O fortalecimento da sociedade civil aparece como alternativa mais aberta aos problemas sociais e à reelaboração de novas formas de relação entre sociedade e Estado. É necessário levar em conta a visão das pessoas e coletividades sobre os seus problemas, bem como sobre as soluções que constroem (Valla, 1998).

Trata-se, nessa nova abordagem dos movimentos, de visualizar novos espaços de mobilização e novas formas de se movimentar ou de ações coletivas, e entender seus significados políticos e culturais ${ }^{4}$. 
A inovação mais recente nos movimentos encontra-se no surgimento de práticas políticas articulatórias das ações localizadas, de redes de movimentos (networks) e na busca de metodologias que permitam entendê-las. Trata-se também de perceber as interconexões entre o local (comunitário) e o global (supranacional, transnacional), o que gera uma cultura política que tem levado os movimentos e suas lideranças "...a alargarem suas visão cotidiana original e a descartarem os remanescentes de seu sectarismo restritivo, se ramificarem em várias direções e juntarem forças em frentes unificadas de ação... Trata-se de passar da análise de organizações sociais específicas, fragmentadas, para a compreensão do movimento real que ocorre na articulação dessas organizações, nas redes de movimentos" (Scherer-Warren, 1993: 22).

O enfoque das redes de movimentos deixa transparecer a evidência de que as redes de movimentos sociais são tributárias de dinâmicas sociais híbridas. Sua existência e funcionalidade fazem transparecer uma hibridação entre o comunitário e o associativo. A dinâmica associativa está fundada no recurso da estruturação organizacional da ação (como nas organizações não-governamentais), enquanto o comunitário está vivo na mensagem religiosa que as igrejas, grupos e entidades difundem.

Essas constatações têm demandado uma visão reticular das mobilizações dos movimentos sociais, suas lógicas sociais plurifuncionais, com dimensões ao mesmo tempo integradoras, utilitárias e contestatórias, que fazem aparecer a multiplicidade de funções que essas redes desenvolvem na condução das suas estratégias.

\section{REDES DE MOVIMENTOS SOCIAIS NA REGIÃO DA LEOPOLDINA}

Nesta pesquisa, os movimentos sociais denominam as ações coletivas desenvolvidas por organizações populares específicas da região da Leopoldina, na cidade do Rio de Janeiro. Porém, para se entenderem os movimentos sociais de uma forma mais dinâmica e próxima da prática cotidiana, é preciso ampliar o foco de análise das organizações específicas para a rede de relações em que estas estão inseridas.

Os movimentos sociais analisados são compostos por organizações não-governamentais (ONGs), associações de moradores, igrejas, Conselho Distrital de Saúde, rádios e jornais comunitários, setores de instituições acadêmicas (Escola Nacional de Saúde Pública - ENSP/Fiocruz - e Universidade Federal do Rio de Janeiro - UFRJ), lideranças populares e alguns grupos informais, como, por exemplo, o Sementinha Serviços Comunitários, que, sendo formado em sua maioria por agentes de saúde, trabalha não só com prevenção e assistência à saúde, como também com alfabetização infantil e de adultos, fitoterapia e rezas para a cura.

As redes de movimentos estudadas nos subúrbios da Leopoldina visam à mobilização de recursos, materiais e simbólicos, para ações de intervenção no quadro das condições de vida da população É uma rede que se fundamenta nos princípios e práticas de educação popular e saúde.

Os indivíduos e grupos considerados na pesquisa foram indicados a partir do elenco de pessoas que têm algum envolvimento com os trabalhos comunitários da região. Grande parte deles se encontra na área de saúde devido ao perfil das instituições de onde partiram os primeiros contatos: a Organização Não-Governamental Cepel (Centro de Estudos e Pesquisas da Leopoldina) e o Elos (Núcleo de Estudos Locais em Saúde), da Escola Nacional de Saúde Pública (ENSP) / Fundação Oswaldo Cruz (Fiocruz). Essas instituições foram escolhidas, por desenvolverem trabalhos junto aos movimentos populares, tendo como enfoque a informação e o conhecimento. Também foram as mesmas instituições que forneceram listas de nomes de pessoas envolvidas nos movimentos sociais da região, nas quais se basearam os contatos com os integrantes dos movimentos.

Levou-se em conta, na análise da estrutura e dinâmica das redes, o pertencimento institucional de cada indivíduo. Embora alguns tenham duplo pertencimento, foi privilegiado aquele por meio do qual os indivíduos se inserem e são reconhecidos no ambiente social das redes.

Os elos da rede foram desenhados a partir da indicação, por cada entrevistado, de até três nomes de pessoas com as quais mantinham contato em função do trabalho popular, desde que estes constassem da lista fornecida pelas instituições.

No processo metodológico da pesquisa, foram estabelecidos dois caminhos que juntos contribuíram para o estudo dos atores envolvidos no nosso universo empírico. O primeiro, através da categoria de campo social ${ }^{5}$, considerando as características pessoais - atributos e discurso dos atores. O outro caminho buscou uma visão relacional desses personagens a partir da análise de redes. Isto significa pensar as pessoas, além do que elas são, em termos de estruturas sociais, considerando que através das relações e das situações criadas a partir desses intercâmbios elas se posicionam com mais flexibilidade na vida social. 
Como forma de operacionalizar as questões levantadas, elaborou-se um sociograma das redes sociais da Leopoldina. A leitura da rede se deu, especialmente, a partir do campo de pertencimento das pessoas: comunidade, $\mathrm{ONG}$, academia e outros.

É importante ressaltar que o desenho da redes sociais da Leopoldina representa um recorte empírico, ou seja, situase em um espaço e tempo definidos. O espaço, neste caso, é parte da região da Leopoldina, e o período, os anos de 1997 e 1998. A rede, no entanto, continua a se movimentar, a fazer novos contatos, fortalecer elos ou enfraquecer laços.

No desenho traçado (figura 1), encontra-se um total de 44 elos e 132 ligações. Considerando o número de seus integrantes (44) e a possibilidade de que cada um deles possa estabelecer elos com cada um dos outros integrantes, a rede traçada possui 1.897 elos potenciais. Os atores foram identificados por números que lhes foram atribuídos e por sinais que representam o campo social a que pertencem.

Não se pode perder de vista que o que se está chamando de redes de movimentos sociais da Leopoldina é apenas um recorte, um fragmento que, como toda rede, tem um alto grau de mutabilidade. Seus integrantes estão também em contato com outras redes e espaços sociais.

\section{DESCRIÇÃO E ANÁLISE DOS DADOS}

A análise de redes sociais trabalha com alguns conceitos desenvolvidos dentro da própria metodologia. Uma definição simples, porém eficaz, de rede é dada por Emirbayer \& Goodwin (1994:1449): "conjunto de relações ou ligações sociais entre um conjunto de atores (e também os atores ligados entre si)". A partir dessa idéia, surgem conceitos fundamentais para a compreensão de um estudo de redes sociais. Em primeiro lugar, chamamos atores ou elos às pessoas que se comunicam em uma dada rede. Novos conceitos próprios desta metodologia surgirão adiante, ao longo da apresentação dos dados.

Como o conceito de redes sociais é um dos pilares do estudo, a idéia de perceber a estrutura social existente no universo empírico através das relações, e não apenas dos atributos individuais, atravessou todo o processo de estudo. Essa foi uma utilização teórico-conceitual das redes sociais.

Foi utilizado o software de análise de redes UCINET $5.0^{6}$, por meio do qual se calcularam algumas medidas que, associadas à conceitualização desenvolvida ao longo da pesquisa, forneceram um retrato mais preciso da realidade estudada.
FIGURA 1

\section{Rede social de contatos - sociograma}

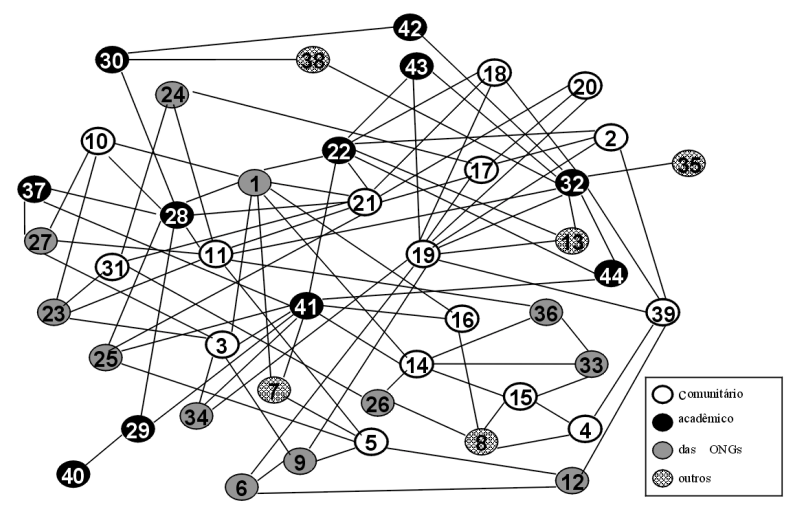

Dentre as possibilidades metodológicas oferecidas pelo programa, foram selecionados dois conceitos cujas medidas interessavam particularmente ao objetivo da análise: cliques e centralidade.

A primeira medida calculada foi a quantidade de relações diretas dos atores (ver quadro 1). As pessoas com maior quantidade de contatos diretos são, certamente, elos importantes em qualquer rede social. Mas a rede é antes de tudo um ambiente de comunicação e troca, que se dá em vários níveis. A informação circula na rede, atingindo os atores também de forma indireta. Isso significa que não só a quantidade de elos diretos (quadro 1) define a posição dos integrantes de uma rede. As duas medidas calculadas ao longo da pesquisa - cliques e centralidade mostraram-se relevantes para a compreensão dos papéis desempenhados por cada ator.

\section{Cliques}

Em qualquer rede social, alguns elos mantêm relações mais estreitas ou mais íntimas. É o que se denomina cliques, que Emyrbayer define como "grupo de atores no qual cada um está direta e fortemente ligado a todos os outros" (1994:1449).

Na leitura geral da rede, as cliques podem representar uma instituição, um (sub) grupo específico e mesmo identificar a movimentação em torno de um determinado problema. Foram considerados como cliques apenas os subgrupos formados por três indivíduos ${ }^{7}$. Com esse cálculo, foram identificadas 19 cliques, todas com pelo menos um representante do campo comunitário. 
No entanto, observando o desenho da rede e confrontando-o com os dados qualitativos da pesquisa, percebe-se claramente a existência de três grandes subgrupos: um formado pelos membros do então Conselho Distrital de Saúde da região (AP 3.1); um outro ancorado em um grupo comunitário de agentes de saúde e rezadeiras (Grupo Sementinha Serviços Comunitários); um terceiro formado por mulheres que estavam em destaque no movimento, em função de uma luta pontual, pela reabertura de um posto de saúde.

Isso significa que, através das medidas e da observação da rede traçada, foi possível verificar os problemas e as soluções que movimentavam aquele grupo, fazendo dele mais do que apenas um aglomerado de pessoas.

Dentre as 19 cliques (de três pessoas cada uma) encontradas, cinco foram chamadas cliques intercampos, por serem formadas por um membro de cada campo social. A importância disso está em identificar essas pessoas como as principais responsáveis por estabelecerem relações e facilitarem as trocas informacionais entre seu campo e os demais.

Em uma rede composta de pessoas de origens e pertencimentos tão diferentes, alguns atores desempenham, por algum tempo, o papel de ponte, fazendo com que a informação circule pelo ambiente total da rede.

\section{Centralidade}

Calcular a centralidade de um ator significa identificar a posição em que ele se encontra em relação às trocas e à comunicação na rede. Embora não se trate de uma posição fixa, hierarquicamente determinada, a centralidade em uma rede traz consigo a idéia de poder. Quanto mais central é um indivíduo, mais bem posicionado ele está em relação às trocas e à comunicação, o que aumenta seu poder na rede.

A centralidade é, então, a posição de um indivíduo em relação aos outros, considerando-se como medida a quantidade de elos que se colocam entre eles. $O$ fato de os indivíduos com mais contatos diretos em uma rede não serem necessariamente aqueles que ocupam as posições mais centrais pode ser explicado através do conceito de abertura estrutural. Um indivíduo com poucas relações diretas pode estar muito bem posicionado em uma rede por meio da utilização estratégica de suas aberturas estruturais.
QUADRO 1

Contatos diretos

\begin{tabular}{ccc}
\hline INDIVÍDUO & CAMPO & № DE ELOS \\
\hline 19 & comunidade & 11 \\
32 & academia & 10 \\
41 & academia & 10 \\
21 & comunidade & 9 \\
01 & ONG & 8 \\
28 & academia & 8 \\
11 & comunidade & 8 \\
22 & academia & 8 \\
03 & comunidade & 6 \\
14 & comunidade & 6 \\
\hline
\end{tabular}

FIGURA 2

Rede social de contatos - cliques

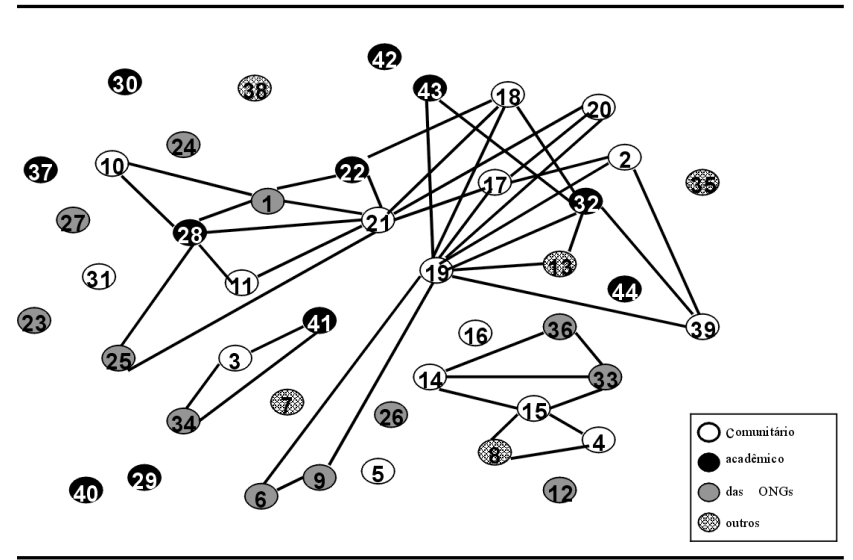

A idéia da utilização de aberturas estruturais baseia-se na otimização das relações e maximização dos contatos, o que interfere diretamente na centralidade de um indivíduo no ambiente das redes.

Imagine-se uma clique formada pelos indivíduos $A, B$ e C. Todos se comunicam entre si. Tem-se, nesse grupo, uma quantidade $x$ de informação nova. Supõe-se agora que $A$ não se comunique com $C$, mantenha contato $\operatorname{com} B$ e com um outro ator, $D$, pertencente a uma outra clique. Nesse caso, a quantidade de novidade cresce consideravelmente, porque foi eliminado um elemento de redundância $(C)$ e acrescentado um elo de fora $(D)$. 
Como em uma rede social os indivíduos não obtêm informação apenas dos seus contatos diretos, pode-se observar, pelo desenho ao lado (figura 3), que, com a mesma quantidade de contatos, $A$ recebe mais informação no segundo caso, porque ela otimiza seus contatos. Em termos práticos, a informação que vinha de $\mathrm{C}$ era redundante. Ao estabelecer contato com um outro ator, $A$ não perde as informações de $C$ (que vêm através do seu contato com B) e ainda abre caminho para informações vindas de outros ambientes.

A esse espaço dos "não-contatos" chamamos abertura estrutural ou "ausência de relação entre atores em uma rede (o elemento crucial da estrutura da rede)" (Emirbayer; Goodwin,1994:1449).

Esse conceito recupera, de alguma forma, a valorização dos elos fracos: "Os elos fracos são pertinentes para compreender os atores sociais, que não seriam descritos em função de seus elos fortes" (Granovetter, 1973: 1360-1380).

No caso das redes sociais da Leopoldina, pode ser utilizado um exemplo para mostrar a eficácia dos aberturas estruturais. As figuras seguintes mostram a rede pessoal de dois indivíduos - I-32 e I-21 - da rede social traçada. Está sendo aqui adotada a definição de rede pessoal dada por Ruth Kohn, segundo a qual se trata da identificação das relações de um indivíduo com as pessoas citadas por ele, mas também as relações entre estas últimas (Charlot, 1994: 2).

É preciso lembrar que, na rede em questão, cada personagem pôde citar no máximo três nomes - modo de coleta normalmente sugerido pela metodologia de redes -, embora certamente eles conheçam muitas outras pessoas. Além disso, em uma rede social, os atores não obtêm informação apenas das pessoas com as quais se relacionam diretamente.

As figuras 4 e 5 mostram, portanto, os contatos diretos e os primeiros contatos mediados dos dois elos selecionados. Foram destacadas as pessoas citadas pelos indivíduos $32 \mathrm{e}$ 21 e aquelas citadas por estas.

Percebe-se (figuras 4 e 5) que, embora I-32 tenha mais contatos diretos - 10, no total - do que I-21 - que tem 9 -, este último tem uma rede pessoal maior (30 contra 23). Uma das conclusões a que se pode chegar a partir deste exemplo é que I-21 mantém contatos estratégicos, isto é, faz uso dos aberturas estruturais, atinge mais pessoas com menos contatos diretos e, portanto, com menos esforço. Ele otimiza suas relações.
FIGURA 3

Abertura estrutural

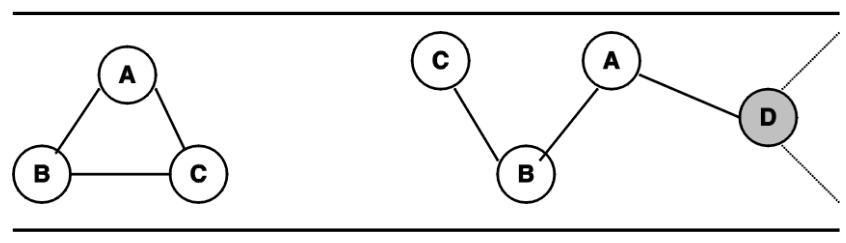

FIGURA 4

Rede social de contatos - abertura estrutural

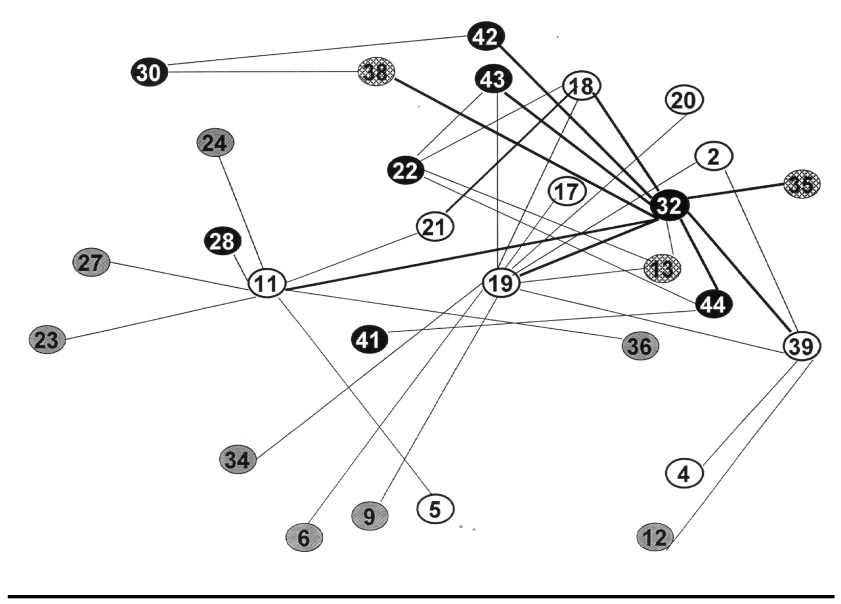

FIGURA 5

Rede social de contatos - abertura estrutural

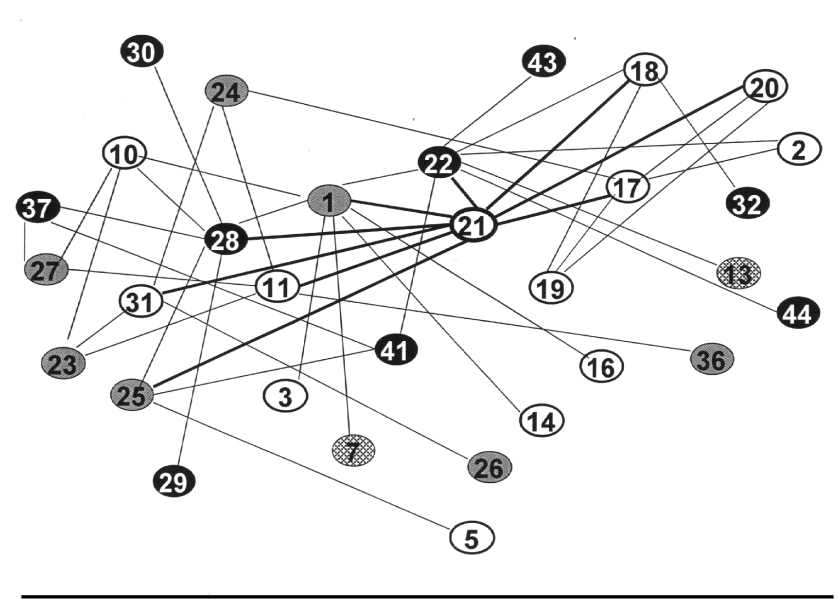


Utilizando ou não os espaços das aberturas estruturais, existem diferentes tipos de centralidade em uma rede social. Para os objetivos da pesquisa, foram estudadas três modalidades: centralidade da informação, da intermediação e de proximidade.

Apesar de serem calculados aqui os índices de centralidade, seu contrário, ou seja, a posição periférica, também tem seu papel na dinâmica das redes sociais. É através da periferia que uma rede pode se abrir para novas informações, para a comunicação com ambientes externos.

\section{Centralidade da informação}

Um indivíduo é central em relação à informação, quando, por seu posicionamento, recebe informações vindas da maior parte do ambiente da rede, o que o torna, entre outras coisas, uma fonte estratégica.

$\mathrm{Na}$ redes sociais da Leopoldina, as pessoas com maior centralidade da informação são aquelas que, nos diferentes campos (a comunidade é o que mais aparece), mais se destacam no trabalho popular, seja no papel de lideranças, seja no de articuladores do movimento. Sua posição estratégica é devidamente reconhecida pelos demais participantes da rede. O elo com maior índice de centralidade da informação foi I-19 (ver quadro 2).

O alto índice de centralidade da informação faz com que esses atores tornem-se referências dentro do movimento popular, cada um desempenhando sua função. Seja à frente de uma ONG, como I-01, na liderança de uma luta pontual, como I-11 - pela reabertura do posto de saúde da Vila do João - ou circulando e participando de eventos em toda a região, como I-03, essas pessoas aumentam a movimentação, a comunicação e a capacidade de mobilização da rede.

\section{Centralidade de proximidade (closeness centrality)}

Em relação à proximidade, um ator é tão mais central quanto menor o caminho que ele precisa percorrer para alcançar os outros elos da rede. Isso mede, em última análise, a sua independência em relação ao controle de outros.

Destaca-se, na rede social traçada na Leopoldina, como indivíduo mais central nessa categoria, uma liderança popular (I-10) que emergia no movimento naquele momento, em função de uma luta pontual que chamava a atenção de toda a rede. Isso significa que ela caminhou da periferia em direção ao centro, conseguindo alcançar com certa facilidade os demais elos. A informação circulou por todo o ambiente da rede, e uma luta localizada movimentou-a por inteiro.
QUADRO 2

\section{Centralidade da Informação}

\begin{tabular}{ccc}
\hline NÚMERO & CAMPO & ÍNDICE \\
\hline 19 & comunidade & 1,92 \\
01 & ONG & 1,91 \\
21 & comunidade & 1,90 \\
41 & academia & 1,87 \\
22 & academia & 1,84 \\
11 & comunidade & 1,84 \\
28 & academia & 1,82 \\
32 & academia & 1,77 \\
03 & comunidade & 1,67 \\
17 & comunidade & 1,66 \\
\hline
\end{tabular}

\section{QUADRO 3}

Centralidade de proximidade

\begin{tabular}{ccc}
\hline NÚMERO & CAMPO & PROXIMIDADE \\
\hline 11 & comunidade & 48.28 \\
21 & ONG & 47.73 \\
28 & comunidade & 47.19 \\
41 & academia & 45.16 \\
32 & academia & 44.68 \\
19 & academia & 44.68 \\
34 & comunidade & 43.75 \\
25 & ONG & 41.58 \\
03 & ONG & 41.18 \\
\hline
\end{tabular}

Embora em posições diferenciadas, os atores que têm destaque em relação à centralidade de proximidade (ver quadro 3) são basicamente os mesmos que os dados mostraram serem centrais no caso da informação. Há apenas duas novidades no rol dos personagens centrais: os indivíduos 25 e 34, que possuem na sua história profissional o trabalho em ONGs. Sua alta centralidade de proximidade, portanto, vem ressaltar o papel de mediação e apoio desempenhado pelas ONGs nos movimentos populares, o que faz com que alguns de seus membros circulem por diversas áreas, estabelecendo contatos estratégicos que podem ser ampliados quando estes deixam aquelas organizações. 
Análise de redes sociais - aplicação nos estudos de transferência da informação

\section{Centralidade de intermediação (betweeness centrality)}

A centralidade de intermediação (betweeness centrality) é o potencial daqueles que servem de intermediários. Calcula o quanto um ator atua como "ponte", facilitando o fluxo de informação em uma determinada rede. Um sujeito pode não ter muitos contatos, estabelecer elos fracos, mas ter uma importância fundamental na mediação das trocas. O papel de mediador traz em si a marca do poder de controlar as informações que circulam na rede e o trajeto que elas podem percorrer.

Cabe recuperar, neste ponto, o conceito de abertura estrutural. Em primeiro lugar, porque essa posição de intermediário provavelmente se deve a uma capacidade de otimizar os contatos, agindo de forma estratégica. "A intermediação de um ponto em presença de dois outros atores se define por sua faculdade de se situar sobre o caminho ou os caminhos geodésicos (isto é, de menor distância) ligando estes dois pontos" (Degenne \& Forsé, 1994: 158). Em segundo lugar, porque o papel de mediação implica um exercício de poder, de controle e filtro das informações que circulam na rede.

Na análise destes dados, o destaque é o indivíduo I-39 (ver quadro 4), que aparece como o segundo maior intermediário na rede, tendo destaque pela primeira vez. Seu tão demarcado papel de mediação se deve, muito provavelmente, ao seu trabalho efetivo em uma rádio comunitária.

\section{CONSIDERAÇÕES FINAIS: REDE, INFORMAÇÃO E CONHECIMENTO}

O emprego da metodolodia de análise de redes sociais aliada à leitura qualitativa permitiu reunir elementos que apontam para os modos de comunicação, a produção de conhecimentos e o uso das informações pelos grupos e entidades organizados das redes de movimentos sociais da região de Leopoldina.

Os indivíduos identificados como mais centrais nas redes sociais de Leopoldina são aqueles responsáveis pela maior mobilização e dinamização das redes e dos movimentos. Eles mediam as trocas e facilitam o fluxo da informação, fortalecendo a ligação da rede como um todo. Por outro lado, os personagens periféricos colocam as redes em contato com o mundo exterior, abrindo suas possibilidades de expansão e movimentação.

Quando consideradas as cliques formadas pelas redes, sejam as menores, identificadas através do software UCINET 5.0, ou as maiores (três exatamente) visualizadas através do sociograma traçado, percebemos o quanto a maior
QUADRO 4

\section{Centralidade de intermediação}

\begin{tabular}{ccc}
\hline NÚMERO & CAMPO & ÍNDICE \\
\hline 19 & comunidade & 206.13 \\
39 & comunidade & 200.69 \\
21 & comunidade & 172.09 \\
01 & ONG & 157.05 \\
32 & academia & 145.17 \\
28 & academia & 136.22 \\
14 & comunidade & 134.43 \\
11 & comunidade & 134.40 \\
41 & academia & 132.32 \\
03 & comunidade & 130.69 \\
\hline
\end{tabular}

interação entre determinados microgrupos pode fortalecer a capacidade de mobilização das redes. Em especial, notamos que destes grupos surgem personagens-ponte, que tomam para si o papel de colocar os elos em contato, aumentando a capacidade e a eficácia da comunicação.

A análise de redes pode ser aplicada no estudo de diferentes situações e questões sociais. Esta representação das redes humanas permite perceber como uma rede de muitas unidades é capaz de originar uma nova ordem, que não pode ser entendida apenas por suas unidades individuais. Porém, no interior do todo, a rede não deixa de ser uma ligação de fios individuais onde cada um constitui uma unidade em si, único em forma e posição.

A margem de decisão do indivíduo inserido em uma determinada rede social, no entanto, está sempre presa à distribuição do poder, à estrutura da dependência e das tensões no interior de seu grupo. A influência de uma pessoa sobre outras pode ser grande, mas a autonomia da rede em que ela atua é incomparavelmente mais forte.

No estudo dos movimentos populares, o enfoque das redes, aliado ao emprego complementar da metodologia de análise de redes sociais e da análise qualitativa, levou a perceber que esses movimentos estão colocando em prática uma nova compreensão do conhecimento e da informação. 
Nessas redes de movimentos, organiza-se um novo conjunto de ações e representações que conformam um campo de intervenção social em que se evidencia a importância do conhecimento prático para a compreensão e criação do poder de transformação da realidade vivida e das próprias instituições. Por sua natureza, esse conhecimento prático faz parte do conhecimento, ou seja, é parte integrante do mecanismo social de qualquer trabalho ou atividade e está ligado à ação.

O caminho analítico e interpretativo percorrido ao longo de toda a pesquisa nos levou a concluir que à formação das redes de movimentos sociais corresponde a criação de redes de conhecimentos que alimentam e dão sentido informacional às visões e estratégias de ação e de direção dos agentes. Os conhecimentos se constituem como matérias informacionais, que, pelas suas qualidades imateriais, articulam entre si o que foi notado (observado) ou experimentado pelos agentes nas suas práticas, dentro do ambiente da sociedade em que essas redes se movimentam.

\section{REFERÊNCIAS BIBLIOGRÁFICAS}

BARNES, J. A. Social networks. (An Addison-Wesley Module in Anthropology) Module 26, 1972, p. 1-29.

BOTH, Elizabeth. Família e rede social. 2. ed. Rio de Janeiro : F. Alves, 1976.

BOURDIEU, Pierre. O campo científico. In: ORTIZ, Renato (Org.). Sociologia. São Paulo : Ática, 1983. p. 122-155.

Brasil, 1989.

. O poder simbólico. Lisboa : DIFEL, Rio de Janeiro : Bertrand

. Ce que parler veut dire; l'économie des échanges linguistiques. Paris : Fayard, 1982.

BOURDIEU, Pierre, WACQUANT, Loïc J. D. Réponses; pour une anthropologie réflexive. Paris: Seuil, 1992.

CAMPBELL, Karen E., MARSDEN, Peter V., HURLBERT, Jeane S. Social Resources and socioeconomics status. Social Network, North Holland, v. 8, p. 97-117, 1986.

CASTELLS, M. La cuestión urbana. Buenos Aires : Siglo XXI, 1974.

CHARLOT, Bernard (coord.). L'école et le territoire: espaces, nouveaux enjeux. Paris: Armand Colin, 1994

COLONOMOS, Ariel (org.) Sociologie des réseaux transnationaux; communautés, entreprises et individus : lien social et système international. Paris : l'Harmattan, 1995.

DEGENNE, Alain, FORSÉ, Michel. Les réseaux sociaux; une analyse structurale en sociologie. Paris : Armand Colin, 1994.

DEROY-PINEAU, Françoise. Reseaux Sociaux : bibliographie commentée. Montréal : Université de Montréal, 1994. mimeo.
ELIAS, Norbert. A sociedade dos indivíduos. Rio de Janeiro : Zahar, 1994.

EMIRBAYER,Mustafa, GOODWIN, Jeff. Networ analysis, culture and the problem of aagency. American Journal of Sociology, v.99, n.6, p.1411-1454, 1994

ENCARNAÇÃO, Juliana L. Redes e papéis sociais nos processos de transferência da informação. Rio de Janeiro, 1999. Diss. ( Mestrado em Ci. da Inf.). CNPq/IBICT-UFRJ/ECO. Orient.: Regina M. Marteleto

GRANOVETTER, Mark. The strength of weak ties. American Journal of Sociology. Vol 78, no 6, maio 1973: p. 1360-1380.

LIPNAK, Jessica, STAMP, Jeffrey. Networks, redes de conexão : pessoas conectando-se com pessoas. São Paulo : Aquarela, 1992.

LOPES, Sônia Aguiar. A teia invisível; informação e contra-informação nas redes de ONGs e movimentos sociais. Rio de Janeiro, 1997. Tese (Doutorado em Ci. da Inf.) - IBICT/CNPq - ECO/UFRJ. Orient.: Gilda M. Braga, Ma. Nélida G. de Gómez

MARTELETO, Regina Maria. Cultura, Espaço e Textualidade; relações intercampos, redes sociais e novas configurações comunicacionais e informacionais. Rio de Janeiro : Programa de PG em Ciência da Informação - CNPq/ IBICT - UFRJ/ECO, 1998. Projeto Integrado de Pesquisa, Relatório Final.

ROGERS, E. M., KINCAID, D. L. Communication network; toward a new paradigm for research. New York : Free Press, 1981.

SENNA FILHO, Arthur Ribeiro de. Organizações Não-Governamentais de assessoria popular, novos movimentos sociais, Estado e democracia. R. Serviço Social e Sociedade, n. 45, p. 43-65, 1994.

SCHERER-WARREN, Ilse. Redes de Movimentos Sociais. São Paulo: Edições Loyola, 1993. 
Análise de redes sociais - aplicação nos estudos de transferência da informação

\section{NOTAS}

${ }^{1}$ Projeto Integrado de Pesquisa "Cultura, Espaço e Textualidade; relações intercampos, redes sociais e novas configurações comunicacionais e informacionais", financiado pelo CNPq. Programa de Pós-Graduação em Ciência da Informação, CNPq/IBICT - UFRJ/ECO.

${ }^{2}$ Os antropólogos J. A. Barnes \& E. Bott, autores clássicos e pioneiros dos estudos de redes sociais, mostram que o conceito de redes pode ser empregado junto a diversos marcos conceituais. É mais um ferramental de análise do que propriamente um conceito analítico, ou construto teórico reconhecido. Ambos apontam para a necessidade de uma pesquisa de caráter etnográfico, para fazer funcionar o conceito. (Cf. Barnes, J. A.,1971; Bott, E., 1976). M. Emirbayer faz uma revisão de estudos de redes sociais, ressaltando seus pressupostos teóricos. Apesar do crescimento dessa área de estudos, o autor afirma que ela não possui bases teóricas e críticas consistentes, sendo fortemente marcada pela empiria. Segundo o autor, a análise de redes sociais “... não é uma "teoria" formal ou unitária que especifica leis, proposições ou correlações distintas, mas antes uma estratégia ampla para investigar a estrutura social." (Cf. Emirbayer, M., 1994, p. 1414)

${ }^{3}$ M. Castells cunhou, nos anos 70, a expressão "movimentos sociais urbanos" para se referir aos movimentos de reivindicações coletivas a partir das contradições que se situam fora da área imediata da produção - aquelas que ocorrem no nível do consumo coletivo. Essas contradições propriamente urbanas estão relacionadas: a) à organização social do espaço, com a grande concentração de pessoas sem recurso algum nas grandes cidades e a inexistência de mecanismos econômicos para sua reprodução e de mecanismos sociais para o seu controle; b) à produção, distribuição e gestão dos meios de consumo coletivo (habitação, transporte, saúde, educação, equipamentos coletivos etc.) (Cf. CASTELLS, M., 1974).
${ }^{4}$ Scherer-Warren, I., 1993. A autora, ao se referir às novas abordagens dos movimentos sociais, lembra que as modificações nas abordagens não são o mero fruto do repensar teórico. "Há transformações nas realidades internas dos países latino-americanos e externas com repercussões transnacionais sobre a prática efetiva dos movimentos sociais. Internamente, destacam-se os movimentos de democratização política e de reformas institucionais. Externamente, as transformações no socialismo real trazem perplexidades em relação às utopias dos movimentos populares na América Latina.. As modificações históricas conduzem ao repensar das teorias." (Cf. p. 21-22, grifos nossos)

${ }^{5} \mathrm{O}$ conceito de campo é central na sociologia de P. Bourdieu e pode ser aproximado aos conceitos de rede e configuração em N. Elias. (Ver Déchaux, J. H., 1993; Santiso, J., 1995). P. BOURDIEU assim se refere ao conceito de campo: "Eu poderia, deformando a célebre fórmula de Hegel, dizer que o real é relacional: o que existe no mundo social são relações - não as interações ou os elos intersubjetivos entre os agentes, mas as relações objetivas que existem "independentemente das consciências ou das vontades individuais", como dizia Marx. Em termos analíticos, um campo pode ser definido como uma rede, ou uma configuração de relações objetivas entre as posições. Estas posições são definidas objetivamente na sua existência e nas determinações que elas impõem aos seus ocupantes, agentes ou instituições, pela sua situação (situ) atual e potencial na estrutura de distribuição das diferentes espécies de poder (ou de capital) cuja possessão comanda o acesso aos benefícios específicos que estão em jogo no campo, e, ao mesmo tempo, pelas suas relações objetivas com as outras posições (dominação, subordinação, homologia etc.). Nas sociedades altamente diferenciadas, o cosmos social é constituído pelo conjunto desses microcosmos relativamente autônomos, espaços de relações objetivas que são o lugar de uma lógica e de uma necessidade específicas e irredutíveis àquelas que regem os outros campos." (Bourdieu, P.; Wacquant, L. J. D., 1992, grifos nossos)

${ }^{6} \mathrm{O}$ Ucinet é distribuído por Analytic Technologies, 306 S. Walker, Columbia SC 29205, USA.

${ }^{7}$ De acordo com a configuração do software empregado. 